\title{
Cadeia logística integrada e vantasem competitiva: o caso carvão do mineral em Beira - Moçambique
}

\section{Integrated logistics chain and competitive advantage: the mineral coal in Beira - Mozambique case}

\author{
LÉO TADEU ROBLES \\ SÉrgio SAMPAIO Cutrim" \\ CARLOS JoÃo DIASIII
}

\begin{abstract}
Resumo Este trabalho apresenta uma reflexão sobre a estratégia de integração logística na exportação de carvão no Porto de Beira, Moçambique da VALE. Esta integração se dá no sistema mina, ferrovia e porto e nas dimensões técnica; logística e institucional/legal do transporte de carvão da Mina de Moatize até o Terminal de Carvão do Cais 8 do Porto da Beira. A VALE adota como estratégia a verticalização de suas cadeias logísticas de exportação como fonte de sua competitividade nos mercados internacionais em que atua, a exemplo do minério de ferro do Brasil. Em Moçambique, na primeira fase de exploração de concessão de mina de minério de carvão, a empresa adotou um sistema logístico parcial de integração com o controle das operações na mina, recuperação da operação da ferrovia existente até o Porto da Beira e a operação contratada do terminal portuário. A VALE está implantando o Corredor Nacala (Norte de Moçambique) composto por uma ferrovia de $912 \mathrm{~km}$, que atravessa o Malauí e dá acesso a um porto de águas profundas. Durante a implantação, a VALE está utilizando a alternativa do Porto da Beira através de ferrovia existente remodelada. Esta solução logística apresenta riscos, por exemplo, menor controle sobre prazos de entrega e qualidade do carvão; não atendimento dos volumes anuais programados, o que implica em gerenciamento estreito e permanente das
\end{abstract}

Universidade Federal do Maranhão (UFMA), São Luís/MA - Brasil.

II Universidade Federal do Maranhão (UFMA), São Luís/MA - Brasil.

III Companhia Vale S/A - Moçambique. 
suas dimensões. A empresa considera estratégico atuar no setor de carvão e para operação no país vem investindo em infraestrutura e capacitação de pessoas e fornecedores.

Palavras-chave: Logística integrada; Carvão mineral; Vantagem competitiva; MoçambiQUE; VALE.

Aвstract This paper presents an insight about integrated logistics strategy in the mining coal exportation from Porto of Beira in Mozambique, managed by VALE. The integration comprises the mine-railway-port system considered in the technical, logistics and institutional/ legal dimensions referred to the transportation of coal from the Moatize's mines to the Dock 8 Coal Terminal at Port of Beira. VALE is implementing the Nacala Corridor (Mozambique's Northern region) which comprises a $912 \mathrm{~km}$ railway, crossing Malawi and accesses a deep water port. Meanwhile construction, VALE is using the alternative of Port of Beira reached by the existing railway, which it was rebuilt. This logistics solution has risks, for instance, less control upon deliveries schedules; programmed volumes not accomplished, which implies in a requiring a close and permanent management regarding its dimensions. VALE considers strategic to be on coal mining industry and to operate in the country, it has been investing in infrastructure, people developing as well local suppliers.

Keywords: Integrated logistics; Mineral coal; Competitive advantage; Mozambique; VALE.

\section{INTRODUÇÃO}

A VALE, criada em junho de 1942, como empresa estatal, foi privatizada em 1997. Atualmente, opera em cerca de 30 países e é considerada uma das maiores empresas de mineração do mundo, sendo líder na produção e comercialização de minério de ferro e pelotas, com investimentos logísticos na Argentina, no Brasil, na Indonésia, em Moçambique e em Omã. A VALE também é produtora global de concentrado de cobre, carvão, bauxita, alumina, alumínio, potássio, caulim, manganês e ferroligas (Vale, 2012).

A Figura 1 apresenta as principais localizações da VALE no mundo.

No desempenho de suas atividades, a VALE adota uma estrutura logística integrada, com a ligação de suas minas, por ferrovias próprias a portos próprios de exportação. A verticalização da sua cadeia logística faz parte da sua estratégica de concorrência de mercado global altamente competitivo. Por exemplo, o minério de ferro brasileiro precisa compensar as maiores distâncias ao principal mercado mundial, a Ásia, em comparação com outros fornecedores localizados mais próximos, por exemplo, os do continente australiano.

No âmbito desta estratégia, em 2004, a empresa foi vencedora de licitação pública internacional para exploração e exportação de carvão em Moçambique. Atualmente, a empresa conta com cerca de 18.000 empregados, entre próprios e de terceiros, sendo que a mina de carvão de Moatize tem capacidade medida de 11 milhões de t/ano, sendo 8,5 milhões de t de carvão metalúrgico e 2,5 milhões de t de carvão térmico. 
Figura 1 - Locais onde a VALE se apresenta

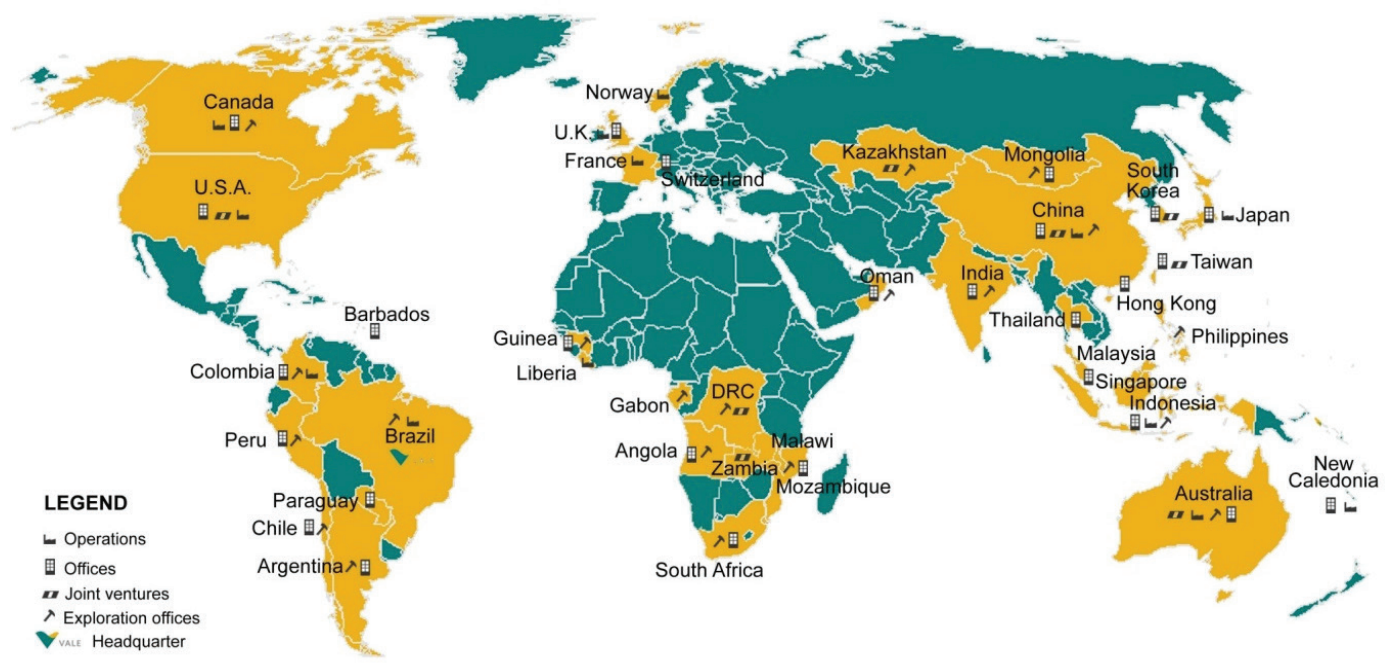

Fonte: Vale (2016).

Este artigo focaliza o sistema atual de integração nas dimensões técnica, logística e institucional legal, voltado para a movimentação de exportação do carvão da mina de Moatize em Moçambique para o Porto da Beira, localizado no centro de Moçambique, especificamente pelo TCC8 - Terminal de Carvão do Cais 8. O TCC8 é concessionado pela VALE S/A. e tem capacidade de escoamento de seis milhões de t/ano. A empresa está investindo em projeto de infraestrutura logística, o Projeto Corredor Nacala, composto pela recuperação de $682 \mathrm{~km}$ da ferrovia entre Moçambique e Malauí, a implantação de terminal marítimo em Nacala-a-Velha de $230 \mathrm{~km}$ de linhas férreas novas. (Ver Figura 4). O projeto prevê a expansão da capacidade de movimentação de carvão para até 18 milhões de t/ano. (VALE, 2016).

A Figura 2 apresenta o mapa de Moçambique onde se percebe a localização de Moatize na província de Tete, o Porto da Beira em Sofala e Nacala, ao norte na província de Nampula.

O estudo exploratório tem como metodologia um estudo de caso, partindo da revisão bibliográfica, da análise de relatórios técnicos, da identificação e análise de projetos de implantação da solução logística da VALE em Moçambique, sendo realizadas entrevistas com especialistas e executivos da VALE. O levantamento de informações e o estudo técnico-documental se referem a documentos disponibilizados pelo TCC8, tais como, projetos de implantação dos sistemas, documentos de negociação entre a VALE e o Governo Moçambicano e documentos relacionados a procedimentos internos e procedimentos operacionais.

O estudo de caso, segundo Yin (2001), constitui-se em um estudo empírico de investigação de fenômeno atual em seu contexto de realidade e, no qual, as fronteiras entre o fenômeno e o contexto não são claramente definidas, utilizando-se várias fontes de evidência. E recomenda que o método seja utilizado em situações onde os comportamentos relevantes não podem ser manipulados, mas onde é possível fazer observações diretas e entrevistas sistemáticas e, assim, se caracteriza pela capacidade de lidar com uma completa variedade de evidências - documentos, artefatos, entrevistas e observações. 
Figura 2 - Mapa de Moçambique

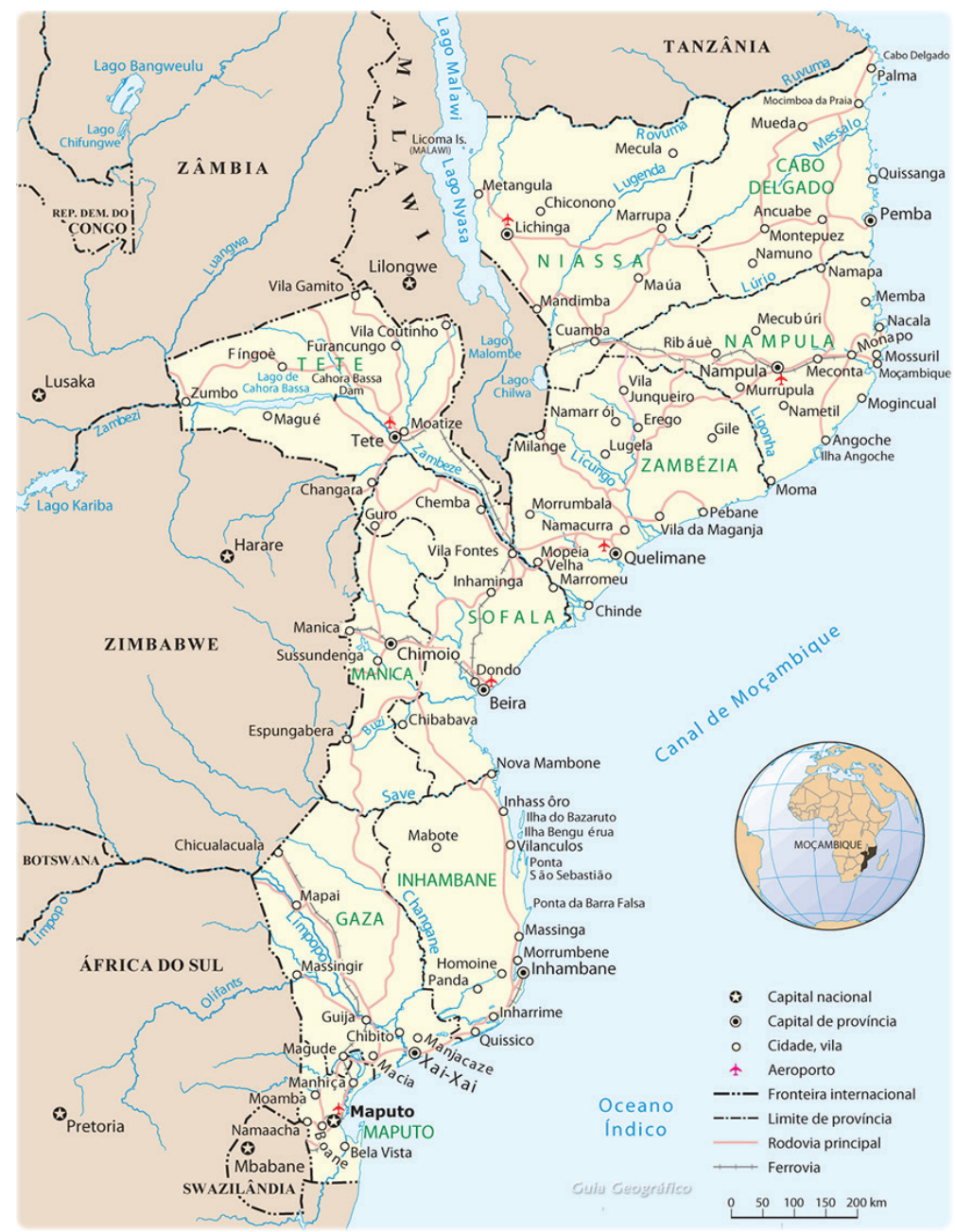

Fonte: AFD - Agence Française de Développment, 2016.

Neste caso, a oportunidade do estudo se apresentou com a realização de curso lato sensu em Engenharia Portuária em São Luís (MA) pela Universidade Federal do Maranhão em 2012 em parceria com a VALE.

\section{FUNDAMENTAÇÃO TEÓRICA}

A concepção da logística é de sistema integrado em que seus componentes básicos, ou seja, transporte, armazenagem, embalagem, manuseio de materiais, sistemas de informação, gestão de inventários, questões fiscais e ambientais são gerenciados de forma conjunta, pois os resultados acontecem com a exploração de trocas compensatórias de custos entre esses componentes. (ROBLES, 2016). 
Os componentes logísticos são identificados a partir da definição da necessidade e os requisitos básicos para um sistema logístico, e sua análise é expandida para estabelecer uma base funcional, com a identificação das suas necessidades de recursos, isto é, equipamentos, softwares, instalações, pessoas e elementos de infraestrutura. O caso focalizado neste artigo é o do sistema integrado do Porto de Beira (TCC8).

Bowersox et al. (2006) apresentam a logística como responsável pela coordenação de atividades funcionais da empresa, desde a avaliação de um projeto de rede, a localização de instalações, sua estrutura interna e quantidade, a gestão dos componentes logísticos para se conformar um processo de criação de valor para os clientes. Marchesini e Alcântara (2012) definem como função logística a oferta de serviços aos clientes com qualidade superior e baixo custo, de forma que se agregue valor aos produtos no ponto de vista dos clientes.

O transporte, sem dúvida, é um dos principais componentes logísticos, representando a maior parte dos custos e tempos logísticos e, assim, com desempenho importante na qualidade dos serviços ao cliente, e, conforme apontam Bowersox et al. (2006), mesmo com o avanço da tecnologia de comunicações e da troca de informações em tempo real, o transporte continua sendo fundamental para o resultado logístico.

A gestão de estoques está relacionada com as características das operações de produção e de distribuição e estabelece as condições de quanto, quando e como pedir. (CHING, 2009). Se por um lado, estoques sempre representam custos e devem ser controlados, por outro, representam segurança em relação aos processos de recebimento de matérias-primas (relação com fornecedores), de processamento de pedidos e da produção e de distribuição na relação direta com clientes.

As inter-relações entre o transporte, a armazenagem repercutem na gestão de estoques na configuração de trocas compensatórias (trade-offs) de custos de cadeias logísticas. Ou seja, embora transporte se apresente como o produto em movimento e a armazenagem, o produto parado, a decisão do modo de transporte (mais rápido ou mais lento, por exemplo) condiciona o volume e o tempo em que um produto será armazenado na sua disponibilização para produção ou consumo, ou seja, custos de transporte afetam os de armazenagem e em consequências os níveis e custos dos estoques.

Um exemplo é o sistema logístico que envolva um porto, o sistema de armazenagem intermediária tem como função a regulação dos fluxos terrestres de produtos e a chegada, operação e saída de navios. (CUTRIM et al., 2014) Sua função é a redução de estoques em trânsito e armazenados.

A Figura 3 apresenta um resumo de uma cadeia logística, conforme proposto por Ballou (2006). 
Figura 3 - Configuração de cadeias logísticas

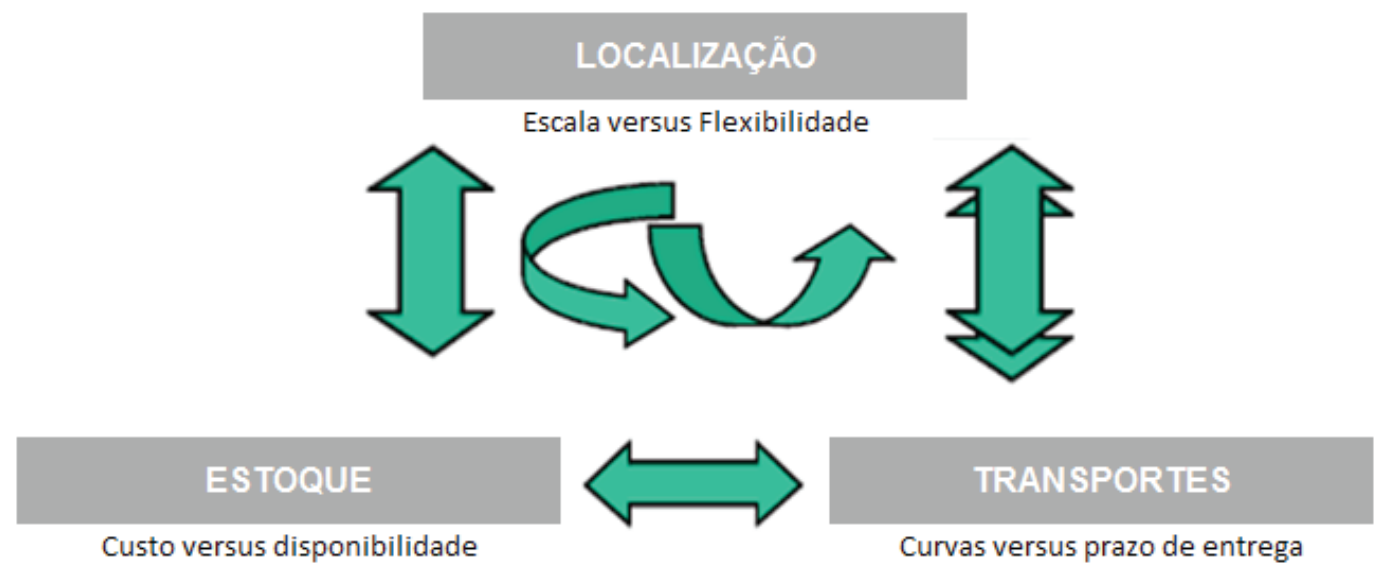

Fonte: Adaptado de Ballou (2006).

\section{SisTEMAS LOGÍsTICOS}

Sistema foi definido por Blanchard (2008) como um conjunto de elementos interconectados, que formam um todo organizado. Vindo do grego, o termo "sistema" significa "combinar", “ajustar", "formar um conjunto”. O INCOSE (International Council on Systems Engineering) definiu sistema como a construção ou conjunto de elementos diferentes que, juntos produzem resultados que não podem ser obtidos por meio desses elementos de forma isolada. (INCOSE, 2016). Os elementos, ou partes, podem se referir a pessoas, equipamentos, instalações, políticas e documentos, ou seja, todas as coisas necessárias para produzir resultados ao nível de sistema.

Blanchard (2008) destaca a existência de vários tipos de sistemas: (1) sistemas naturais referentes a processos naturais; (2) sistemas feitos pelo homem que incluem uma ampla variedade de características; (3) sistemas físicos são constituídos de componentes reais ocupando espaço; e (4) sistemas fechados, relativamente autossuficientes, não interagindo com o seu ambiente.

Este artigo aborda sistemas feitos pelo homem, "físicos por natureza e dinâmicos em operações” (BLANCHARD, 2008, p. 31) e que juntos produzem resultados não atendidos pelos sistemas de forma individual. No caso, tem-se a extração de minério de carvão da mina, a transferência via ferroviária a um terminal portuário e sua transferência offshore para navios de grande porte e encaminhamento aos importadores.

\section{SERVIÇOS LOGÍSTICOS INTEGRAdOS}

A logística integrada é reconhecida na vinculação entre uma empresa e seus clientes e fornecedores. As informações recebidas de clientes fluem na empresa por meio das atividades de vendas, previsões e pedidos, subsidiando a implantação dos planos de produção e de suprimentos. (BOWERSOX et al., 2006). Para o suprimento de materiais se inicia um fluxo de bens e valores que termina na transferência de propriedades de produtos acabados aos clientes, que 
consubstancia um fluxo financeiro entre as empresas envolvidas. Assim sendo, o processo se compõe de três fluxos de ações inter-relacionadas: o fluxo de materiais, o fluxo de informações e um fluxo financeiro que viabiliza essas relações. O conceito de logística integrada é demonstrado na Figura 4.

Figura 4 - Logística integrada.

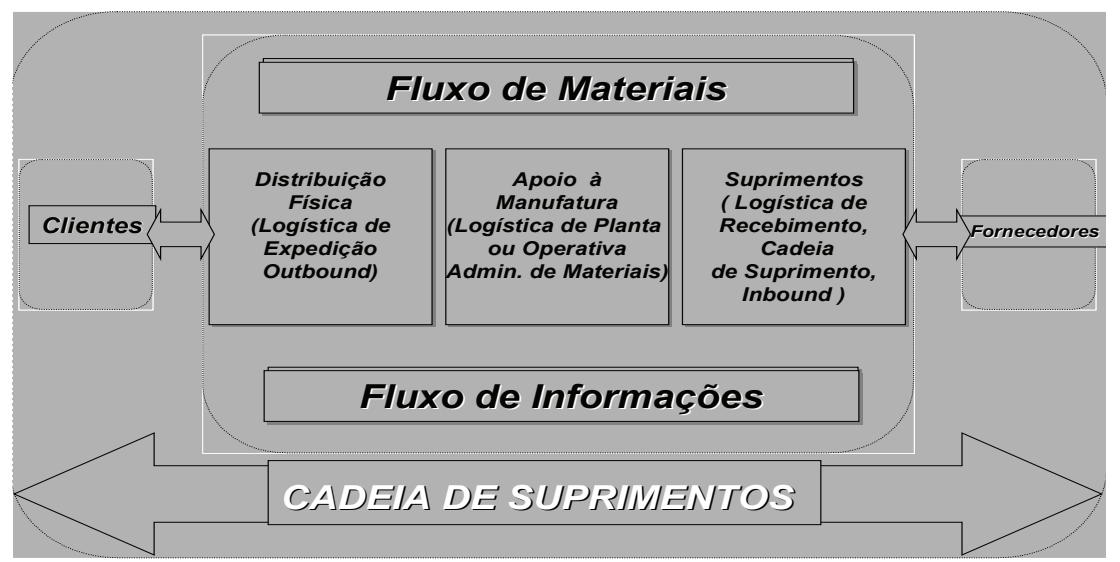

Fonte: Adaptado de Bowersox et al. (2006).

A missão do gerenciamento logístico é planejar e coordenar todas as atividades necessárias para atingir os níveis desejados de qualidade e de serviços prestados ao menor custo possível, ou como apresenta Christopher (2007), meio pelo qual as exigências dos clientes são atendidas pela coordenação dos fluxos de materiais e de informação ao mercado, desde a empresa, até fornecedores. Assim a logística se apresenta na empresa como sistema em que as necessidade de mercado são traduzidas em estratégia e plano de operação.

\section{VANTAGEM COMPETITIVA}

Em uma concepção sistêmica a logística é entendida como fonte de vantagem competitiva da empresa. O conceito da vantagem competitiva se opõe ao conceito clássico de vantagem comparativa, de Ricardo (1982), em que o comércio internacional não necessariamente é estabelecido com base em vantagens absolutas. Ou seja, os países exportarão os bens nos quais têm maior produtividade relativa do trabalho (têm vantagem comparativa na sua produção) e importarão os bens nos quais apresentam menor produtividade relativa do trabalho (não têm vantagem comparativa na sua produção).

Ao contestar estas teorias clássicas, Porter (1989) propõe a abordagem além do conceito de vantagem comparativa, em que a vantagem competitiva dos países reflete o conceito de competição, com mercados segmentados, produtos diferenciados, diversidades tecnológicas e economias de escala. No âmbito empresarial, Porter (1998) aponta que a vantagem competitiva advém do valor adicionado aos produtos/serviços e propõe como ferramenta de avaliação a cadeia de valores para identificar a partir das atividades empresariais as que agregam valor do ponto de vista dos clientes.

A posição de competição, conforme resumem Ito e Gimenez (2011), é resultado da criação de compatibilidade entre as atividades executadas e gerenciadas de forma integrada. A 
vantagem competitiva se mostrará sustentável se materializa a agregação de valor aos clientes de forma não replicável pela competição na inter-relação com fornecedores, canais de distribuição e clientes. (PORTER, 1998).

O conceito de integração vertical foi difundido por Slack et al. (2013) e se refere ao grau de controle que determinada empresa tem sobre seus fatores de produção ou sobre a distribuição ou utilização dos produtos e serviços produzidos e prestados. A integração vertical pode, portanto, ser entendida com a progressão da empresa em sua cadeia de suprimentos e pode assumir dois tipos: integração vertical a montante: quando o controle se dá no sentido dos fatores de produção da empresa e; integração vertical a jusante: quando o controle se dá à frente na cadeia produtiva, isto é, na distribuição ou a transformação dos produtos e serviços produzidos pela empresa. (SLACK et al., 2013)

De forma geral, a estratégia da VALE é de, sempre que possível, assegurar a integração vertical de suas cadeias de suprimentos. No caso estudado, a da logística das minas até os portos de exportação, como se mostra a seguir.

\section{Estudo de Caso: a exportação de Carvão pelo Porto da Beira (TCC8)}

O estudo da solução logística adotada pela VALE em Beira, Moçambique foi dividido em três dimensões: (1) a dimensão técnica; (2) a dimensão logística e; a (3) dimensão institucional/legal.

\section{DIMENSÃO TÉCNICA}

Nesta dimensão, destacam-se os projetos de construção da mina, a solução ferroviária, via contrato com os CFM e a concessão e construção do TCC8. A mina de carvão de Moatize é um projeto greenfield, ou seja, implantado em área natural sem infraestrutura, tendo sido idealizado desde o projeto conceitual, seu detalhamento, implantação da infraestrutura necessária, incluindo instalações de manutenção, transportadores, fornecimento de água e energia elétrica, vias de acesso e instalação de carregamento ferroviário. Localiza-se na cidade de Moatize, província de Tete, a $575 \mathrm{~km}$ do TCC8, no Porto da Beira.

A Figura 5 mostra a localização da mina de Moatize, a linha férrea de ligação ao porto da Beira.

Figura 5 - Alternativa logística (Linha férrea Sena - Beira).

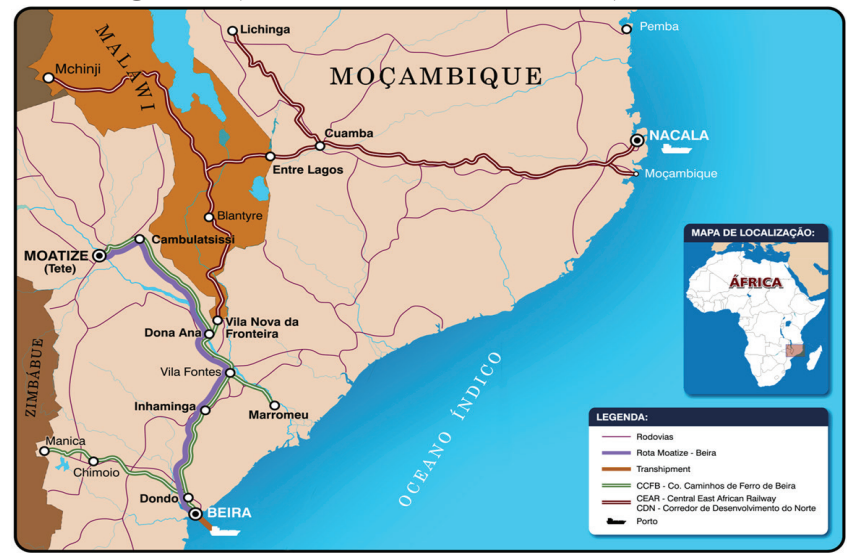

Fonte: Vale (2012). 
A capacidade total nominal de produção da mina de Moatize é de 22 milhões de t/ano de carvão em duas fases. Na primeira fase, a capacidade nominal de produção da mina é de 11 milhões de t/ano. O processo de mineração se iniciou no primeiro semestre 2011 e, em 2013, a mina produziu 4 milhões de t. A VALE está implantando um corredor ferroviário a Nacala, na província de Nacala, onde está construindo um porto de águas profundas compatível com navios de grande calado que operam no comércio internacional de carvão. O corredor ferroviário de $912 \mathrm{~km}$ de extensão passa pelo sul do Malauí e corresponde a $682 \mathrm{~km}$ de reabilitação das linhas existentes e um trecho novo de $230 \mathrm{~km}$.

O porto (TCC8), com capacidade máxima de seis milhões de t/ano de carvão faz parte do Porto da Beira, localizado na província de Sofala em Moçambique, na foz do rio Pungue no Oceano Índico, nas coordenadas $19^{\circ} 48^{\prime} \mathrm{S}$ e $34^{\circ} 50^{\prime} \mathrm{E}$, longitude e latitude, respectivamente. O TCC8, conforme mostra a Figura 6, compreende um subsistema de recebimento das composições (trens) de carvão; de descarga do carvão; de sua estocagem; recuperação e embarque do produto pelo Cais 8 em embarcações menores de transbordo para navios maiores offshore.

Figura 6-Layout do TCC8.

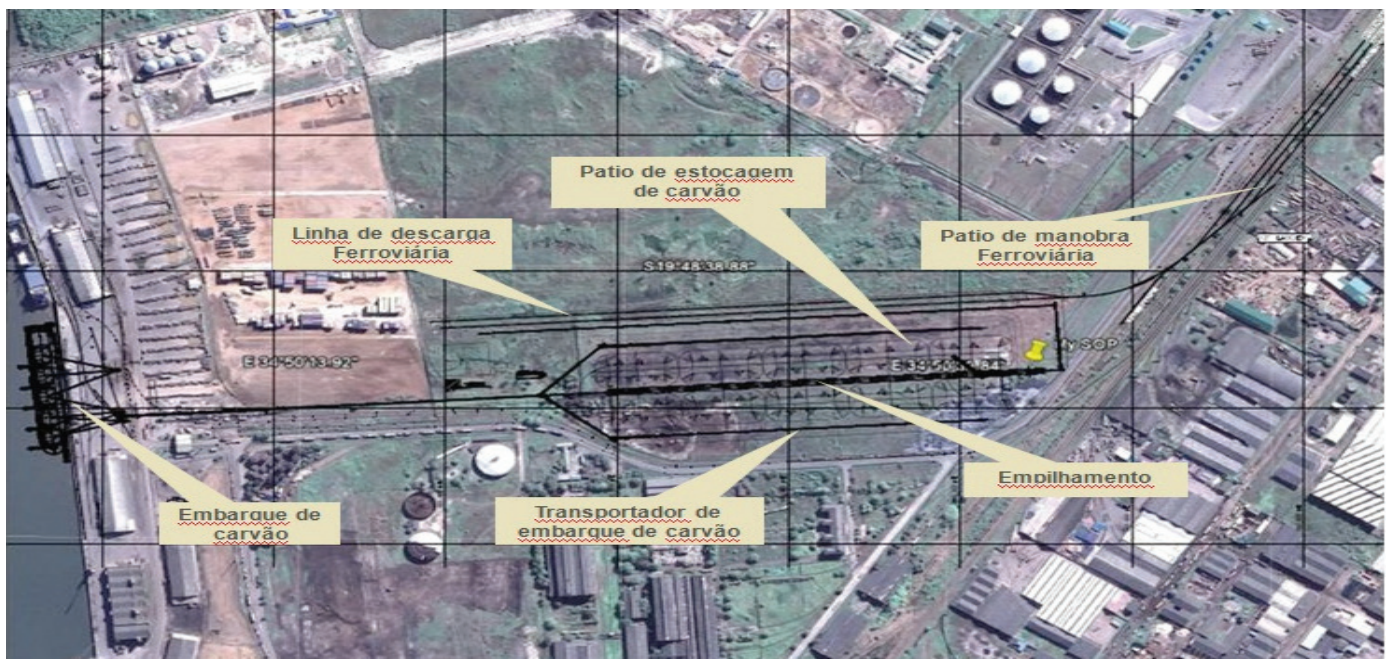

Fonte: Vale (2012).

\section{DIMENSÃO LOGÍSTICA}

A Figura 7 mostra a sequência das atividades desenvolvidas e seus respectivos limites de bateria, ou seja, limitação de responsabilidades dos subsistemas em relação ao sistema total integrado, quais sejam: mina; ferrovia (Linha do Sena) com $575 \mathrm{~km}$; TCC8 e; o transbordo de carvão em alto mar.

Os subsistemas apresentados na Figura 7 são gerenciados e controlados por diversas entidades. O subsistema Mina tem seus processos operacionais totalmente controlados pela VALE, no que diz respeito à extração de carvão, armazenagem intermediária, carregamento de vagões, formação das composições com trem-tipo de 42 vagões, e o controle da movimen- 
tação do carvão por trem até o TCC8. O subsistema ferroviário é de propriedade dos Caminhos de Ferro de Moçambique (CFM), entidade governamental, responsável pela gestão da manutenção e o controle de toda a circulação da linha, no caso a Linha do Sena. A VALE tem essa operação contratada com os CFM. Os limites de responsabilidade destes dois subsistemas representam a primeira interface operacional institucional (VALE/CFM).

Figura 7 - Processos logísticos do sistema logístico Sena-Beira

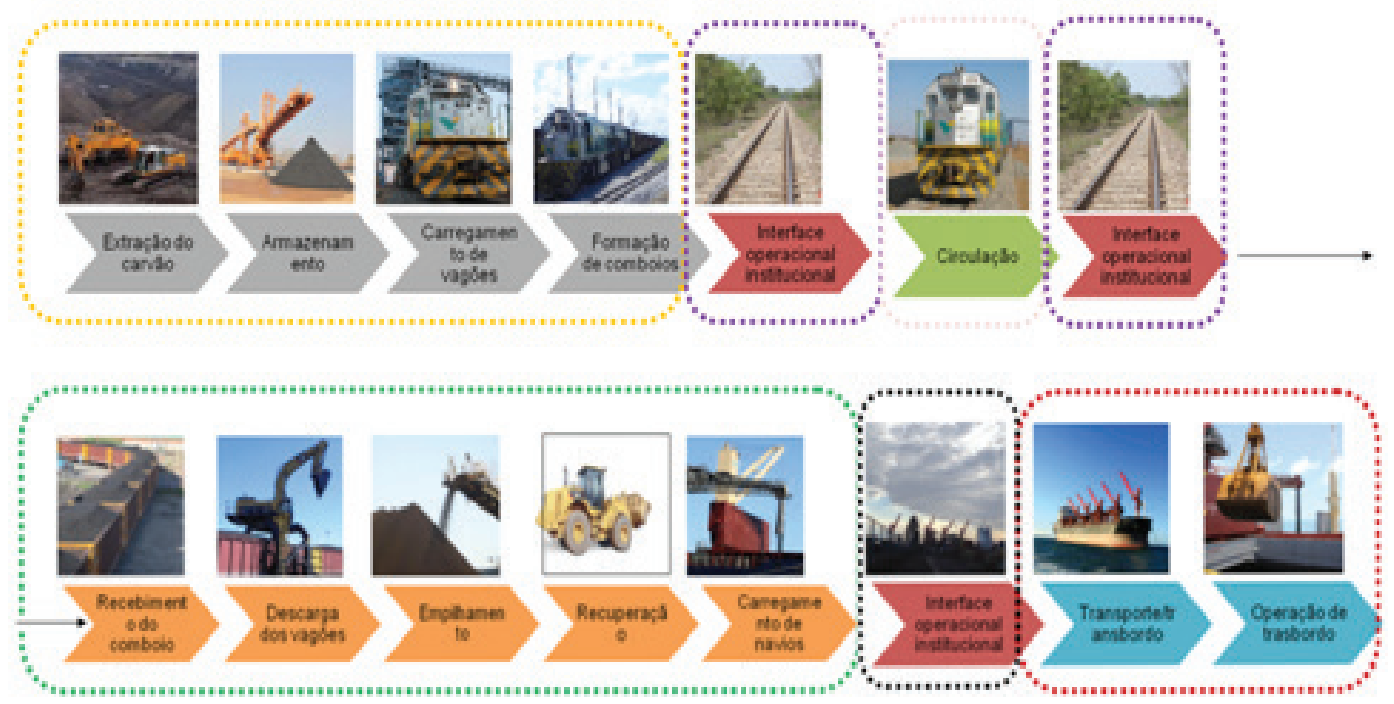

LEGENDA:

"...... Mina de Matize (VALE);

...... Ferrovia mina (Governo de Moçambique);

Operaçăo da frota de comboios (VALE):

. . . ... . Manuseamento TCC8 (Governo de Moçambique);

Ferrovia porto (Governo de Moçambique);

- Transbordo (VALE).

Fonte: Autoria Própria.

A segunda interface institucional (VALE/Operador portuário) acontece a partir da chegada da composição ao TCC8, o qual é gerenciado por uma terceira entidade, a Cornelder de Moçambique, na qualidade de operador portuário, a qual se constitui em uma joint venture privada entre a empresa Portos e CFM e a Cornelder Holdings. Esta última tem origem holandesa e se tem sede em Roterdã. O subsistema porto, TCC8, é responsável pelas operações de recebimento das composições, descarga, estocagem intermediária, recuperação e embarque de carvão nas embarcações para transbordo offshore. A responsabilidade do operador portuário vai até o término do embarque dos navios designados pela VALE.

O subsistema seguinte é o transbordo do carvão em navios transoceânicos fundeados em águas profundas, em que a VALE detêm a gestão completa da movimentação dos navios 
de transbordo até a área de fundeio e da operação de transbordo do carvão para os navios transoceânicos.

Em Moçambique, a VALE e a Rio Tinto (empresa australiana de mineração, uma das maiores do mundo) são as únicas empresas que utilizam o sistema logístico de exportação de carvão pelo TCC8, e a VALE controla $68 \%$ da capacidade total desse sistema em contrato com os CFM. Devido à limitação de profundidade do berço e canal de navegação de entrada do TCC8, a entrada e operação são restritas a navios com capacidade máxima de 35.000 t. Essa desvantagem, em termos de economia de escala e também em relação aos navios graneleiros de transporte oceânico do produto fez com que a VALE monta-se sistema de operação de transbordo marítimo off-shore.

\section{DIMENSÃO INSTITUCIONAL/LEGAL}

A solução logística implantada em Moçambique para exportação de carvão pelo porto da Beira, em termos institucionais, se iniciou em 2004, o Governo de Moçambique lançou um concurso público internacional para concessão da mina de carvão de Moatize, com a VALE como vencedora. Em 2007, o Governo de Moçambique assina um contrato de exploração do carvão de Moatize, no centro do país, com a então Companhia do Vale do Rio Doce (CVRD), atualmente VALE, com concessão de 25 anos, prazo máximo previsto pela lei moçambicana de mineração. Para escoamento do carvão, o Governo de Moçambique teria a responsabilidade de apresentar um sistema logístico, ferrovia e porto.

O sistema ferroviário de Moçambique está dividido em três subsistemas (corredores de desenvolvimento), independentes, cada um possui a sua diretoria executiva, sendo fiscalizados pela entidade estatal Portos e Caminhos de Ferro de Moçambique (CFM) é composto pelo corredor de desenvolvimento do sul do país (CFM-Sul); corredor de desenvolvimento do centro do país (CFM-Central) e corredor de desenvolvimento do norte do país (CFM-Norte).

Em 2011, a VALE e os CFM assinaram um contrato para transporte de carvão da mina para o TCC8 pelo Corredor desenvolvimento do centro. O contrato assinado, em linhas gerais, apresenta as seguintes características: Concessionário: Portos e Caminhos de Ferro de Moçambique (CFM). Modelo de Contrato: Above/Bellow Rail (neste caso, trata-se de contrato de direito de utilização da linha férrea para transporte de carvão, pelo qual a VALE opera seus trens e os CFM têm a responsabilidade de garantir manutenção da via permanente e controle de toda a circulação. Capacidade: Com reabilitação de vias, 6,5 Mtpa (milhões de t/ano). Distância: $575 \mathrm{~km}$. Bitola: 1,067mm

Em 2009, em virtude das obras de construção do terminal portuário não terem sido iniciadas pelos CFM e as obras de exploração da mina de Moatize já em fase avançada e com previsão de início de operação para 2011, a VALE para atender compromissos internacionais, negociou a implantação do TCC8.

O Memorando de Entendimento para implantação do TCC8, em linhas gerais, compreendeu: Capacidade de manuseio e embarque carvão de 6 milhões de t/ano de carvão; acordo contratual para utilização exclusiva do TCC8 de cinco anos, durante os quais a VALE e a 
Rio Tinto seriam os únicos usuários do terminal; a partilha da capacidade útil do TCC8 de 68\% para VALE e 32\% para Rio Tinto, com base em contratos "Take or Pay" firmados entre essas empresas e o Governo de Moçambique (proprietário e operador do terminal); pagamento de tarifa competitiva ao operador portuário por parte das empresas e a VALE responsável pela implantação do TCC8.

Contratos take-or-pay se referem a acordos entre um vendedor e um comprador. Em que este é obrigado a pagar, independentemente do uso do bem ou do serviço e serve como salvaguarda ao vendedor que, como no caso, reserva parte da capacidade de prestação de serviços a usuários. (RODRIGUES JR., 1997).

A ação da VALE se enquadra em sua estratégia de integração vertical de sua cadeia logística, ou seja, a propriedade da mina, o direito de utilização da linha ferroviária de ligação e segurança na utilização do TCC8. O projeto de Nacala segue a mesma diretriz.

\section{Resultados e discussões}

O projeto carvão de Moatize da VALE é composto pelas atividades de mineração e escoamento da produção, via ferrovia, embarque no terminal portuário, TCC8 e transbordo offshore, integrando os sistemas mina, ferrovia e porto em três dimensões: a técnica; a logística, e a institucional.

$\mathrm{Na}$ dimensão técnica, a VALE foi responsável pela idealização e implantação dos projetos e extração mineral, do TCC8, e operação de transbordo, nas seguintes características:

A mina de Moatize: Concepção - projeto greenfield; Capacidade - 11 milhões de t/ano de carvão (fase 1); Equipamentos de mineração - aquisição de equipamentos novos (elevada tecnologia).

A ferrovia: Concepção - recuperação e utilização de linha férrea existente; Capacidade - 6,5 milhões de t/ano de carvão (fase 1); Equipamentos - aquisição de locomotivas de segunda mão.

O TCC8: Concepção - construção do TCC8; Capacidade - 6 milhões de t/ano de carvão (fase 1); Equipamentos - aquisição de equipamento novos (elevada tecnologia).

A operação do transbordo: Concepção - construção de dois navios para transbordo, e montagem de um sistema de boias de atracação para os navios transoceânicos.

Assim, de forma semelhante ao apontado por Robles et al. (2012), o sistema logístico implantado pela VALE para exportação do carvão segue a estratégia de integração vertical da empresa da exportação do minério de ferro da mina de Carajás (PA) pelo Terminal Marítimo de Ponta da Madeira (TMPM), localizado em São Luís (MA). De forma semelhante, a empresa opera o sistema ligado ao Porto de Tubarão em Vitória (ES). No caso, a exportação do carvão de Moatize, a gestão da cadeia logística é integrada (recepção do minério, armazenamento intermediário, instalações de carga dedicadas, manuseio e operações portuárias e marítimas) atende essa estratégia de integração vertical, em que a VALE tem o controle de todos os subsistemas da cadeia, de modo a assegurar vantagem competitiva no processo.

$\mathrm{Na}$ dimensão logística, a VALE é responsável pelo transporte de carvão da mina para o TCC8, e pela operação de transporte e transbordo de carvão nos navios transoceânicos. 
Na dimensão institucional, a VALE conta com contrato de concessão para exploração da mina de Moatize, de operação conjunta da ferrovia com os CFM, em que a VALE opera suas locomotivas e os CFM controla toda circulação e garante a manutenção da linha férrea.

No TCC8, a VALE é um dos dois utilizadores do porto, com contrato com os CFM para manuseio da sua carga. O Quadro 1 apresenta, de forma resumida, as responsabilidades dos intervenientes do sistema logístico nas dimensões destacadas.

Quadro 1- Responsabilidade dos intervenientes do sistema logístico.

\begin{tabular}{|l|l|l|l|}
\hline Dimensão & Técnica & Logística & Institucional \\
\hline Mina & VALE & & VALE \\
\hline Ferrovia & VALE & VALE & VALE \\
\hline & Operação dos trens & CFM & CFM \\
\hline $\begin{array}{l}\text { - } \\
\text { TCC8 }\end{array} \quad$ Manutenção da Via Permanente da circulação & CFM & CFM \\
\hline $\begin{array}{l}\text { Manobra dos trens } \\
\text { Manuseio do carvão (descarga, } \\
\text { empilhamento, recuperação e } \\
\text { embarque) }\end{array}$ & VALE & VALE & VALE \\
\hline Transbordo & CFM & CFM & CFM \\
\hline
\end{tabular}

Fonte: autoria própria.

A mina é propriedade da VALE, responsável por sua exploração (processos extração de carvão, beneficiamento, armazenamento, carregamento dos vagões), por sua vez a ferrovia (Sena - Beira) é propriedade dos CFM, o TCC8 e as operações de manuseio do carvão são da responsabilidade da empresa Portos e CFM e, por fim, a operação de transporte e transbordo de carvão em alto mar da responsabilidade da VALE.

O terminal de carvão implantado no Porto da Beira, o TCC8 é um terminal público controlado pelo Governo representado pela entidade de Portos e Caminhos de Ferro de Moçambique - CFM, o que, na ótica de usuário tem as seguintes características:

O Memorando de Entendimento de implantação do TCC8 corresponde a um contrato tripartite, do tipo Take-or-Pay (contrato operacional em que as partes se comprometem com volume, ou seja, os usuários se comprometem a entregar ao porto determinada quantidade de produto, neste caso, carvão e o operador se compromete a embarcar essa quantidade, com penalizações por eventuais não cumprimentos), envolvendo Portos e CFM (responsável pelo 
terminal), a VALE e Rio Tinto, usuários exclusivos do TCC8 por cinco anos na proporção de $68 \%$ para VALE e 32\% para Rio Tinto.

Dessa forma, o atendimento da primeira fase de implantação do TCC8, com capacidade de embarque de seis milhões de t/ano de carvão, exigiu a integração do sistema logístico para movimentação diária de 14 composições de vagões, sete com vagões carregados ao porto e outros sete de vagões vazios para a mina e comprometimento de berço de 85\% (tempo de operação em relação ao tempo disponível).

Este sistema apresenta riscos que podem ser resumidos: A linha férrea que liga a mina ao porto é uma linha singela (única) recuperada para ser capaz de transportar 6,5 milhões de t/ano de carvão. Esse volume nunca tinha sido antes manuseado pelo sistema; os CFM não possuíam experiência comprovada para garantir a movimentação da demanda acordada; a operação de manuseio de carvão pelo TCC8, considerando esses volumes, foi atividade pioneira no país; a falta na região sul-africana de mão de obra qualificada para estes tipos de atividades e não disponibilidade em Moçambique de empresas para manutenção destes tipos de equipamentos especializados.

\section{CONSIDERAÇÕES FINAIS}

A solução logística implantada em Moçambique para exportação do carvão da Mina de Moatize através TCC8 em suas dimensões técnica, logística e institucional legal evidencia um sistema não controlado direta e exclusivamente pela VALE. Diferente dos sistemas logísticos implantados no território brasileiro, exemplo concreto do sistema de TMPM, o sistema logístico da VALE em Moçambique tem as seguintes características: Sistema Mina (Planta de produção de carvão) - controlado pela VALE; Sistema ferroviário (acessibilidade) - controlado pelos CFM; Sistema Porto (TCC8) - controlado pelo Porto e CFM e Sistema de transbordo (Operação de Transbordo Marítimo) - controlado pela VALE;

Este tipo de configuração de solução logística pode apresentar e riscos de operacionalização, tais como, menor controle sobre a qualidade do carvão; prazos de entrega do carvão; não atendimento dos volumes anuais programados e de exploração dos benefícios associados à economia de escala, exigindo um gerenciamento estreito e permanente das inter-relações.

Dessa forma, o sistema da VALE em Moçambique torna evidente o estabelecimento de forte relação de parceria com os CFM, na transmissão de conhecimentos e trocas de experiências para controle maior da cadeia logística e auxiliar os CFM no desenvolvimento de sistema de operações confiável, de qualidade e sustentável. Em 2013, o sistema de Moatize a TCC8 produziu cerca de três milhões de t, o projeto portuário de Nacala está em fase final de construção e a reabilitação da ferrovia de Moatize a esse porto, em andamento. A VALE reafirma em seu sítio da continuidade das suas operações nesse país. 


\section{REFERÊNCIAS}

AFD - Agence Française de Développment. Disponível em < http://www.afd.fr/webdav/site/afd/ shared/PORTAILS/PAYS/MOZAMBIQUE/mapa-mocambique.jpg>. Acesso em 20 de novembro de 2016.

BALLOU, R. H. Gerenciamento da Cadeia de Suprimentos/Logística Empresarial. 5 a ed. São Paulo: Bookman, 2006.

BLANCHARD, B. S. Systems Engineering Management. $4^{\text {ed }}$. John Wiley \& Sons: 2008.

BOWERSOX, D. J.; CLOSS, D. J.; COOPER, M. B. Gestão logística de cadeias de suprimentos. Porto Alegre: Bookman, 2006.

CHING, H. Y. Gestão de estoques na cadeia logística integrada: Supply Chain. $3^{a}$ ed. São Paulo: Atlas, 2009.

CUTRIM, S. S.; ROBLES, L. T.; ROMA NETO, P.; CUTRIM, S. J. Gestão de falhas na descarga de minérios no Terminal Marítimo de Ponta da Madeira. Revista Ciência \& Tecnologia. V. 17, N. 34, p. 27-50, jan/jun, 2014.

INCOSE - The International Council on Systems Engineering. Disponível em <http://www. incose.org/AboutSE/WhatIsSE>. Acessado em 10 de novembro de 2016.

ITO, N. C.; GIMENEZ, F. A. P. Uma conversa entre Porter e VBR. Framework do valor de transação. Revista Organizações em Contexto. V. 7, N. 14, p. 29-56, jul/dez, 2011.

MARCHESINI, M. M. P.; ALCÂNTARA, R. L. C. Conceituando o serviço logístico e seus elementos. Revista Ciência \& Tecnologia. V. 12, N. 33, p. 65-86, jan/jun, 2012.

PORTER, M. E. Competitive Advantage. Creating and Sustaining Superior Performance. New York: Free Press, 1998.

. A Vantagem Competitiva das Nações. Rio de Janeiro: Campus, 1989.

RICARDO, D. Princípios de Economia Política e Tributação. São Paulo: Abril Cultural, 1982.

RODRIGUES JR., W. A participação privada no investimento em infraestrutura e o papel do Project Finance. Texto para discussão N. 495. IPEA, julho de 1997.

ROBLES, L. T. Cadeias de suprimentos: administração de processos logísticos. Curitiba: Intersaberes, 2016.

ROBLES, L. T.; CUTRIM, S. S.; MOURA, J. P. Vertical integration on logistics chains as competitive advantage: the case of iron ore exportation by Ponta de Madeira (MA) Brazilian port. Anais do WCTRS-SIG 2. Rio de Janeiro, 2012.

SLACK, N.; CHAMBERS, S.; JOHNSTON, R.; BETTS, A. Gerenciamento de Operações e de Processos. Princípios e práticas de impacto estratégico. Porto Alegre: Bookman, 2013. 
YIN, R. K. Estudo de Caso - Planejamento e Métodos. Porto Alegre: Bookman, 2001.

VALE Ports. (2012). Disponível em <http://www.vale.com.br/pt-br/o-quefazemos/

logistica/portos-e-terminais/paginas/default.aspx>. Acessado em 05 de setembro de 2016.

VALE (2016). Disponível em < http://www.vale.com/brasil/PT/aboutvale/across-world/Paginas/default.aspx>. Acessado em 20 de novembro de 2016.

\section{Dados dos Autores}

\section{LÉo TAdeu Robles}

Mestrado e Doutorado em Administração pela Faculdade de Economia e Administração da Universidade de São Paulo. Professor pesquisador associado da Universidade Federal do Maranhão. São Luís/MA - Brasil. leotadeurobles@uol.com.br

\section{Sérgio Sampaio Cutrim}

Mestre em Administração pela Universidade São Marcos. Doutorando em Engenharia Naval e Oceânica pela Universidade de São Paulo. Professor pesquisador da Universidade Federal do Maranhão. São Luís/MA - Brasil. sergio.cutrim@ufma.br

\section{Carlos João Dias}

Graduado em Engenharia Civil pela Universidade Eduardo Mondlaine. Especialista em Engenharia Portuária pela Universidade Federal do Maranhão. Maputo - Moçambique. carlos.joao. dias@vale.com.

Submetido em: 28-11-2016

Aceito em: 8-3-2017 